\title{
HADIS-HADIS TENTANG PUASA 'ASYURA (Suatu Kajian Living Sunnah di Kecamatan Bola Kabupaten Wajo)
}

\author{
Darmiati \\ Muhammad Yahya \\ Andi Darussalam \\ Pascasarjana UIN Alauddin Makassar \\ Kampus II: Jalan Sultan Alauddin Nomor 36 Samata-Gowa \\ Email: darmiati664@gmail.com
}

Abstrak: Pokok masalah penelitian ini adalah bagaimana hadis-hadis tentang hari 'assyüra (studi kajian living sunnah di Kecamatan Bola Kabupaten Wajo)? Adapun masalah yang dipecahkan dalam penelitian ini adalah: 1) Bagaimana gambaran hadis-hadis hari 'āsyüra, 2) Bagaimana bentuk-bentuk tradisi di Kecamatan Bola Kabupaten Wajo pada hari 'àsyürá; dan 3) Bagaimana pengamalan hadis hari 'àsyūrā di Kecamatan Bola Kabupaten Wajo.

Penelitian ini termasuk dalam jenis penelitian lapangan yang bersifat kualitatif dengan menggunakan tiga pendekatan yaitu: 1) Pendekatan historis; 2) Pendekatan sosiologis; dan 3) Pendekatan Fenomenalogis. Sumber data terdiri atas dua sumber data, yaitu data primer dan data sekunder. Sumber data primer adalah sumber data yang diperoleh dari observasi dan wawancara, sedangkan sumber data sekunder adalah sumber data yang diperoleh dari dokumen. Kemudian metode pengumpulan data menggunakan metode observasi, wawancara, dan dokumentasi. Adapun teknik pengolahan dan analisis data melalui tiga tahap, yaitu reduksi data, penyajian data, serta penarikan kesimpulan dan verifikasi.

Hasil penelitian ini menunjukkan bahwa pertama, gambaran hadis-hadis hari 'âsyūra, banyak hadis yang menunjukkan kepada kita sebagai umat Nabi Muhammad saw. perintah untuk melaksanakan ibadah puasa pada hari 'āsyūrä; kedua, bentuk-bentuk tradisi di Kecamatan Bola Kabupaten Wajo yang terkait dengan hari 'āsyüra ada dua yaitu bubur tujuh macam dan pembelian perabot rumah tangga. Bubur tujuh macam tesebut terbuat dari tujuh macam bahan makanan adalah beras ketan, kacang ijo, labu, kacang tanah, pisang, nangka dan ubi jalar. Sedangkan pembelian perabot rumah tangga dengan awalan huruf " $p$ " (dalam bahasa bugis). Seperti, pattapi, passero, dan passering; ketiga, pengamalan hadis 'ásyürā di Kecamatan Bola Kabupaten Wajo bukan dengan cara berpuasa saja, akan tetapi juga melalui berbagai macam cara, seperti zikir mengaji, bersedekah bersedekah. 


\section{PENDAHULUAN}

Hadis merupakan sumber hukum Islam kedua setelah Alquran, ${ }^{1}$ Alquran sendiri memerintahkan untuk mengikuti Rasulullah saw. Sebagaimana ditegaskan dalam ayat sebagai berikut.

1. QS Āli Imrän/3: 32

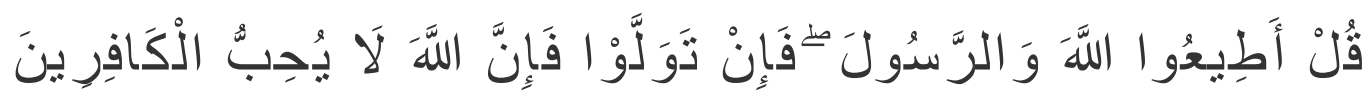

Terjemahanya:

Katakanlah (Muhammad): "Taatilah Allah swt. dan Rasul-Nya; jika kamu berpaling, maka sesungguhnya Allah swt. tidak menyukai orang-orang kafir". ${ }^{2}$

2. QS al- Nisā/4: 80

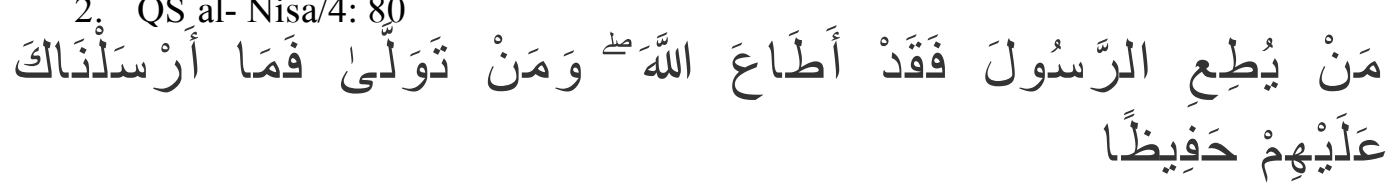

Terjemahanya:

Barangsiapa yang mentaati Rasul itu, sesungguhnya ia telah mentaati Allah swt. dan barangsiapa yang berpaling (dari ketaatan itu), maka kami tidak mengut usmu untuk menjadi pemelihara bagi mereka. ${ }^{3}$

Kedua ayat tersebut menegaskan bahwa taat kepada Allah swt. dengan cara mengikuti ketentuan yang terdapat dalam Alquran, baik berupa perintah-Nya maupun larangan-Nya. Sedang menaati Nabi Muhammad saw. dengan cara mengikuti sunnahNya.

Selain dalam Alquran, perintah untuk menaati Nabi Muhammad saw. juga terdapat dalam hadis Nabi saw. sebagai berikut:

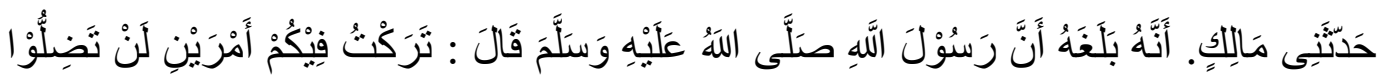

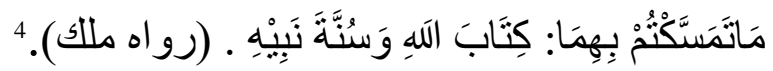

Artinya:

Diceritakan kepadaku dari Malik. Bahwasanya dia menyampaikan bahwa Rasulullah saw. bersabda: "Telah aku tinggalkan untukmu dua perkara,

${ }^{1}$ Yusuf al-Qardhawiy, Taysir al-Fiqh li al-Muslim al-Mu'asharah fi Dau Al-Qurān wa alSunah, diterjemahkan oleh Zuhairi Mizrawi dan Imaduddin Rahman dengan judul Fiqh Taysir: Metode Praktis Mempelajari Fiqhi (Jakarta: Pustaka al-Kautsar, 2001), h. 50.

${ }^{2}$ Kementerian Agama RI, Alquran dan Terjemahnya (Cet. I; Bandung: PT Cordoba Internasional Indonesia, 2012), h. 84.

${ }^{3}$ Kementerian Agama RI, Alquran dan Terjemahnya, h. 118.

${ }^{4}$ Imam Mālik bin Anas, al- Muwatța'(Bairut: Dār al-Fikr, 1989), h. 602. 
kamu sekali-kali tidak akan sesat apalagi berpegang pada keduanya (yakin), kitabullah dan sunnah Nabi-Nya.

Hadis di atas sangatlah jelas bagi kita bahwa sebagai umat Islam harus menaati Rasulullah saw. dengan cara mengikuti sunnah-Nya. Salah satu sunnah Nabi saw. yang perlu kita taati adalah puasa 'asyürā dibulan Muharram, berdasarkan syariat Islam, terdapat sebuah hari yang dikenal dengan istilah yaumu 'āsyürā yaitu hari tanggal sepuluh bulan Muharram, yang menunjukkan sebagai hari yang bersejarah, yang penuh kenangan dan pelajaran yang berharga.

Pada hari 'ásyürā inilah terdapat sebuah sunnah yang telah diajarkan Rasulullah saw. kepada umatnya untuk dilaksanakan sebagai bentuk ibadah dan ketundukan kepada Allah swt. yaitu ibadah puasa, lebih dikenal dengan istilah puasa 'asyürā. Sebagaimana dalam hadis Nabi saw, sebagai berikut:

1) Hadis riwayat Bukahārī

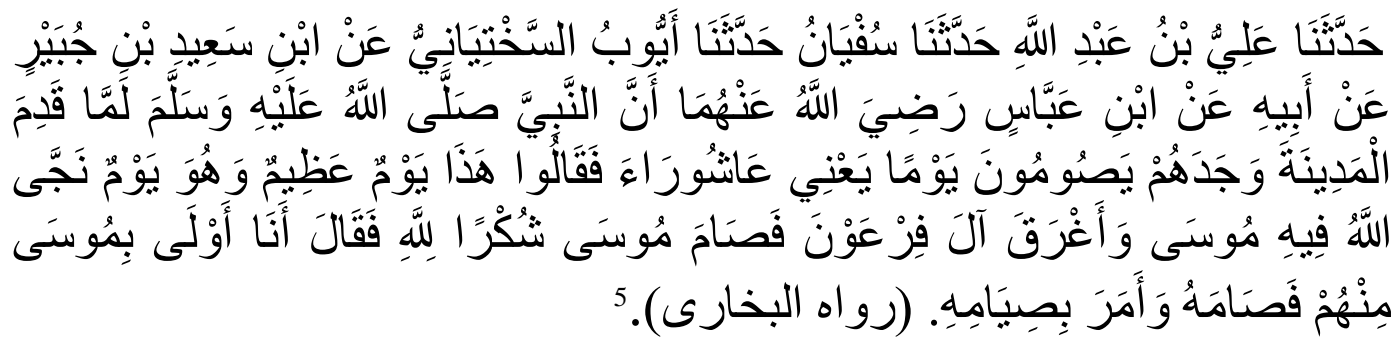

Artinya:

"Telah menceritakan kepada kami Ali bin Abdullah, telah menceritakan kepada kami Ayyub Sakhtiyānìy dari Ibn Said bin Jubair dari ayahnya dari Ibn 'Abbas ra. berkata: Sesungguhnya pada saat Rasulullah saw. sampai di Madinah dia mendapati orang Yahudi dan Nasrani berpuasa pada hari itu, yakni hari 'āsyură. mereka berkata ini adalah hari yang diagungkan yaitu Allah swt. telah melepaskan Musa dan umatnya pada hari itu dari (musuhnya) Fir'aūn dan bala tentaranya, lalu Musa berpuasa pada hari itu, dalam rangka bersyukur kepada Allah swt. Nabi saw. bersabda: Aku lebih berhak terhadap Musa dari mereka. Maka Nabi pun berpuasa pada hari itu dan menyuruh para sahabatnya agar berpuasa juga”. (HR Bukhāri).

2) Hadis riwayat Abū Dāwud

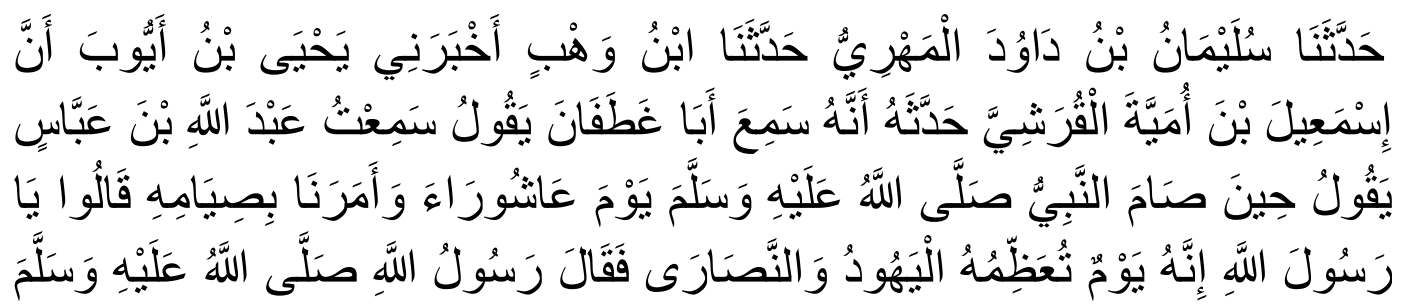

${ }^{5} \mathrm{Abū}$ 'Abdullah Muhammad Ibn Ismā'il al-Bukhārī, Matan al-Bukhāri, Jilid II (Surabaya: Nurul Huda), h. 244. 


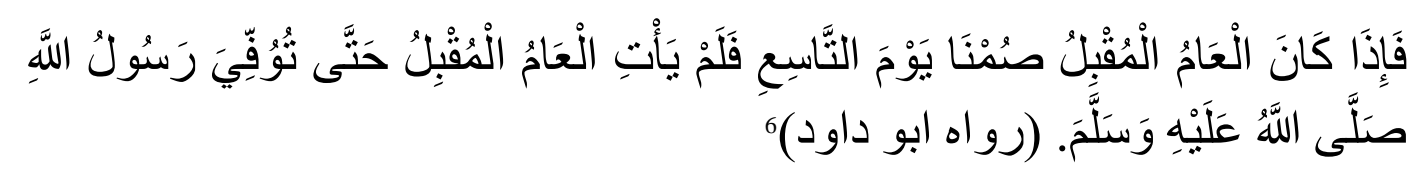

Artinya:

Telah menceritakan kepada kami sulaīmān Ibn Dāud al-Mahriy, telah menceritakan kepada kami Ibn Wahab, telah mengabarkan kepadaku Yahya Ibn Ayyūb bahwasanya Isma'il Ibn Umayyah al-Qurasyiyyah, telah menceritakan kepadaku bahwasanya saya mendengar Abū Ghatfän dia berkata: Saya mendengar 'Abdullah Ibn 'Abbas dia berkata: Pada waktu Rasulullah saw. dan para sahabatnya mengerjakan puasa 'āsyürā, para sahabat menginformasikan kepada Nabi saw. bahwa hari 'äsyürā diagungkan oleh para orang-orang Yahudi dan Nasrani. Maka Nabi saw. bersabda: "Tahun depan insya Allah kami akan berpuasa juga pada hari kesembilan". Akan tetapi sebelum mencapai tahun depan Rasulullah saw. wafat. (HR Abū Dāwud).

Hadis tersebut telah menggambarkan kepada kita bahwa hari 'āsyürà merupakan hari bersejarah yang diagungkan dari masa ke masa, dan sepatutnyalah kita meneladani kebiasaan Nabi saw. Dengan memperingati hari 'asyürā, kita dapat mengambil pelajaran dari perjuangan para Nabi dan Rasul terdahulu. Misi mereka pada dasarnya adalah sama, yakni menegakkan aqidah Islamiyah, menyakini ke-Esaan Allah swt. yang maha pengasih dan maha penyayang. Peristiwa masa lalu merupakan cermin bagi kita untuk berusaha memisahkan kebenaran dan kebatilan, memisahkan yang baik dan buruk, agar senantiasa berada dalam bimbingan-Nya.

Indonesia merupakan negara yang penduduknya terdiri dari berbagai macam agama, suku, bangsa, adat, keyakinan dan kebudayaan. Mereka tersebar diseluruh wilayah Indonesia mulai dari ujung Sabang sampai Merauke. Salah satu suku yang ada di negara ini adalah suku bugis. Suku bugis merupakan salah satu yang mempunyai berbagai macam kekayaan dan keunikan dalam melaksanakan adat istiadat atau tradisi serta kebudayaan mereka. Salah satu adat istiadat atau tradisi yang dilaksanakan secara teratur adalah peringatan bulan Muharram khususnya pada tanggal sepuluh Muharram atau lebih dikenal dengan istilah hari 'àsyürā.

Sepuluh Muharram atau hari 'āsyürā dirayakan oleh sebagian umat Islam dengan cara berpuasa sebagaimana yang telah dijelaskan pada hadis di atas. Namun diberbagai tempat, realita dikalangan masyarakat khususnya di Kecamatan Bola Kabupaten Wajo pada hari 'ásyüră, mereka bukan hanya berpuasa tapi juga melakukan berbagai macam tradisi, seperti membuat "bubur" (bubur tujuh macam).

Dalam tradisi yang lain seperti peneliti dapatkan di Kecamatan Bola Kabupaten Wajo, ketika tiba hari 'äsyürä tepatnya sepuluh Muharram, pasar atau toko peralatan rumah tangga tersebut akan diserbu oleh warga untuk berbelanja dengan anggapan bahwa mereka sedang berburu berkah. Perabot rumah tangga yang dibeli itu beragam tetapi dalam istilah bugis harus diawali dengan huruf "p", seperti pesro (passero), pet (panteng), pmutu (pamuttu), ptpi (pattapi), psEri (passering) ${ }^{7}$ dan lain-lainnya. Ada juga yang beli jenis lain tetapi

${ }^{6}$ Muhammad Muhyī al-din 'Abdu al-Ḥamīd, Sunan $A b \bar{u}$ Dāud, no. 2445, Jilid I (Surabaya: Al-Hidayah), h. 327.

${ }^{7}$ pesro dalam bahasa Indonesia berarti timba. petdalam bahasa Indonesia berarti ember. pmutu dalam bahasa Indonesia berarti wajan. ptpi dalam bahasa Indonesia berarti tampi. dan psEri dalam bahasa Indonesia berarti sapu. 
didominasi berawalan huruf " $p$ " itu selalu ada dengan keyakinan bahwa jenis barang itu bermakna, bisa mendapatkan rezeki lebih banyak.

Inilah sebabnya, pembahasan tentang hari 'àsyürà sangat penting untuk dikaji, mengingat keterkaitannya yang erat dengan aqidah Islamiyah. Memilih ke jalan yang sesuai dengan ajaran Islam dalam hal ini merujuk ke penjelasan Alquran dan hadis khususnya mengenai hari 'äsyürā merupakan sesuatu hal yang disunnahkan oleh Nabi saw. Sehubungan dengan hari 'āsyürā ada beberapa tradisi yang masih kurang jelas dan sebagian kalangan dan peneliti sendiri, sehingga peneliti berpikir bahwa bagaimana hadis menyikapi pembahasan tentang hari 'äsyürā dan segala yang berkaitan dengan itu.

Persoalan yang dikaji adalah: a) Bagaimana gambaran hadis-hadis hari 'āsyürā ?; b) Bagaimana bentuk-bentuk tradisi di Kecamatan Bola Kabupaten Wajo?; dan c) Bagaimana gambaran pengamalan hadis tentang hari 'āsyürā di Kecamatan Bola Kabupaten Wajo?

\section{PEMBAHASAN}

\section{A. Profil Kecamatan Bola Kabupaten Wajo}

Kecamatan Bola merupakan salah satu Kecamatan diantara 14 Kecamatan yang berada di Kabupaten Wajo Sulawesi Selatan. Nama Kecamatan Bola diambil dari nama kerajaan Bola. Rajanya bergelar "Arung Bola" yang berlokasi di daerah Wajo bagian timur. Arung Bola pertama Raja Mawellang Tomanurung, digantikan oleh putranya yang bernama Lasadda. Ketika Lacella memerintah ia bergelar Lacella Datu Bola Datu Tungke'na Alau Wajo. ${ }^{8}$

Kecamatan Bola dari tahun ke tahun sejak tahun 1996 sampai sekarang di nakhodai oleh beberapa camat yang memposisikan sebagai camat pertama Bapak Drs. H. Andi Junaidi Hafid, M.H (Petta Bola) pada tahun 1996-2009 dan dilanjutkan Bapak Syamsul Bahri, S.IP.,M.SI pada tahun 2009-2015 dan dilanjutan Bapak Andi Hasanuddin, S.IP pada tahun 2015-2017 dan pada saat ini yang menjabat sebagai camat Ibu Andi Sariwana, S.E.,M.SI pada tahun 2017 sampai sekarang.'

\section{B. Gambaran Hadis-hadis Hari 'Asyürā}

Adapun gambaran hadis-hadis tentang hari 'āsyürā sebagai berikut:

1. Hadis riwayat Bukhāri

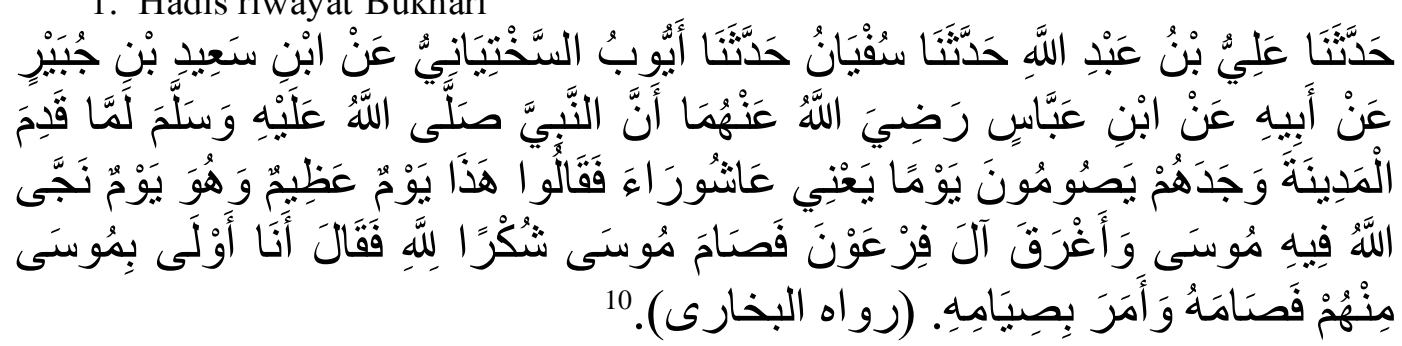

Artinya:

${ }^{8}$ Andi Sariwana (53 tahun), Camat Bola, Wawancara, Solo Kecamatan Bola Kabupaten Wajo, 26 Januari 2018.

${ }^{9}$ Andi Sariwana (53 tahun), Camat Bola, Wawancara, Solo Kecamatan Bola Kabupaten Wajo, 26 Januari 2018.

${ }^{10} \mathrm{Abū}$ 'Abdullah Muhammad Ibn Ismā'il al-Bukhārī, Matan al-Bukhārì, Jilid II (Surabaya: Nurul Huda), h. 244. 
"Telah menceritakan kepada kami Ali bin Abdullah, telah menceritakan kepada kami Ayyub sakhtiyāniyu dari Ibn Said bin Jubair dari ayahnya dari Ibn 'Abbas ra. berkata: Sesungguhnya pada saat Rasulullah saw. sampai di Madinah dia mendapati orang Yahudi dan Nasrani berpuasa pada hari itu, yakni hari 'āsyura. mereka berkata ini adalah hari yang diagungkan yaitu Allah telah melepaskan Musa dan umatnya pada hari itu dari (musuhnya) Fir'aūn dan bala tentaranya, lalu Musa berpuasa pada hari itu, dalam rangka bersyukur kepada Allah swt. Nabi Muhammad saw. bersabda: Aku lebih berhak terhadap Musa dari mereka. Maka Nabi pun berpuasa pada hari itu dan memerintahkan para sahabatnya agar berpuasa juga”. (HR Bukhāri).

حدثنا عبد الله بن مسلمة، عن مالك، عن هثام بن عروة، عن أبيه، عن عائشة

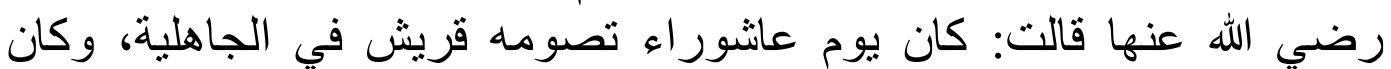

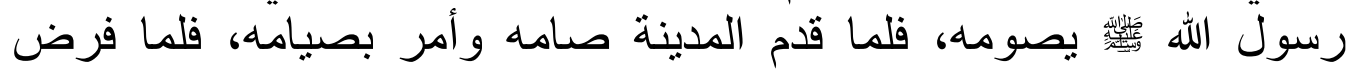
رمضان ترلك يوم عاشور اء، فمن شاء صامه ومن شاء تركه، (رواه البخاري

Artinya:

Menceritakan kepada kami Abdullah bin Maslamah, dari Mālik, dari Hisyām bin Urwah, dari bapaknya, dari Aisyah ra., beliau berkata: Pada hari 'āsyürā (sepuluh Muharram), orang-orang Quraisy Jāhiliah berpuasa, dan Rasulullah saw. pun berpuasa. Maka ketika beliau sampai di Madinah, beliau berpuasa dan memerintahkan umatnya untuk berpuasa. Setelah datang kewajiban puasa Ramadhan, maka Nabi saw. tidak mewajibkan berpuasa pada hari itu. Barangsiapa yang berkeinginan berpuasa maka kerjakanlah, dan barangsiapa yang berkeinginan tidak puasa maka tinggalkanlah. (HR Bukhāri).

حدثنا أبو معدر حدثنا عبد الوارث حدثنا أبوب حدثنا عبد الله بن سعبد بن

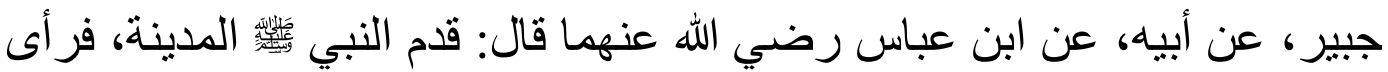

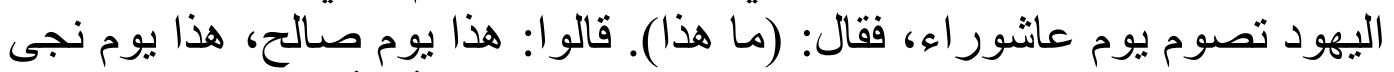
الله بني إسرائيل من عدوهم، فصامه موسى. قال: (فأنا أحق بموسى منكم).

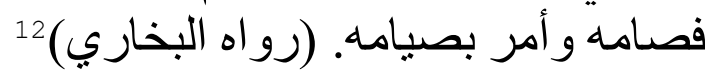

Artinya:

Menceritakan kepada kami Abū Ma'mar, menceritakan kepada kami Abdul Wariș, menceritakan kepada kami Ayyub, menceritakan kepada

${ }^{11} \mathrm{Abu}$ Abdillah Muhammad bin Ismail bin Ibrahim bin al-Mughirah bin Bardizbah alJa’fi al-Bukhari, Șậị Bukhārí, Jilid I (Semarang: Toha Putra), h. 250.

${ }^{12} \mathrm{Abu}$ Abdillah Muhammad bin Ismail bin Ibrahim bin al-Mughirah bin Bardizbah alJa'fi al-Bukhari, Șaḥị Bukhārī, h. 251. 
kami Abdullah bin Sa'id bin Jubair, dari Ibnu Abbas ra., ia berkata: bahwa, ketika Nabi saw. datang ke Madinah, mendapatkan orang Yahudi berpuasa satu hari, yaitu hari 'assyüra (sepuluh Muharram). Maka Nabi bertanya: "Hari apa ini"? Mereka menjawab: Ini adalah hari yang agung yaitu Allah swt. menyelamatkan Bani Israil dari musuh-musuhnya, maka Nabi Musa as. berpuasa sebagai bukti syukur kepada Allah swt. Rasulullah saw. kemudian berkata, saya lebih berhak mengikuti Musa as. dari kalian semua. Maka beliau berpuasa dan memerintahkan (umatnya) untuk berpuasa. (HR Bukhāri).

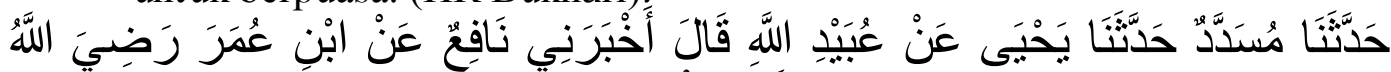

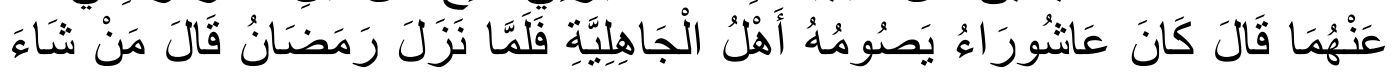

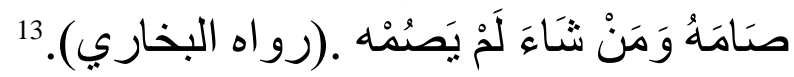

Artinya:

Telah menceritakan kepada kami Musaddad, telah menceritakan kepada kami Yahya dari 'Ubaidullah dia berkata; Telah mengabarkan kepadaku Nāfi' dari Ibnu 'Umar ra. dia berkata; "Dahulu hari 'āsyürā adalah hari orang-orang jahiliah pergunakan untuk puasa, tatkala turun bulan ramadian, beliau bersabda: "Barang siapa yang ingin berpuasa 'āsyūrā hendaklah ia berpuasa, dan bagi yang tidak ingin, silahkan tinggalkan." (HR Bukhārì).

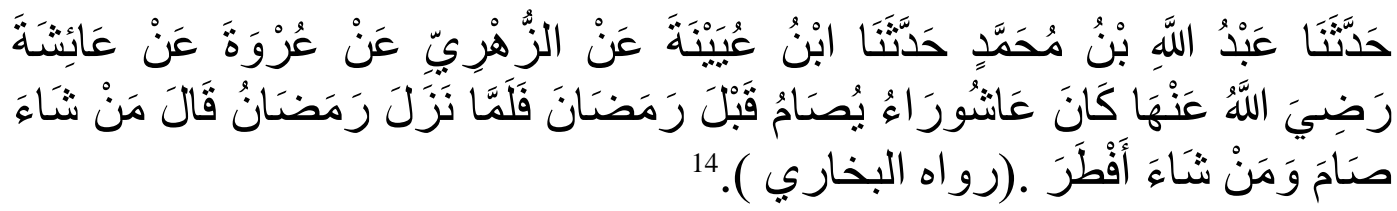

Artinya

Telah menceritakan kepada kami 'Abdullah bin Muhammad, telah menceritakan kepada kami Ibnu Uyainah dari az Zuhri dari 'Urwah dari Aisyah ra.; "Dahulu hari 'āsyūrā adalah hari-hari yang dipergunakan orang-orang jahiliah untuk melakukan puasa sebelum ramadhan, ketika datang bulan ramadhan, beliau bersabda: "Barang siapa yang ingin berpuasa 'āsyūrā hendaklah ia berpuasa, dan bagi yang tidak ingin, maka berbukalah ". (HR Bukhāri).

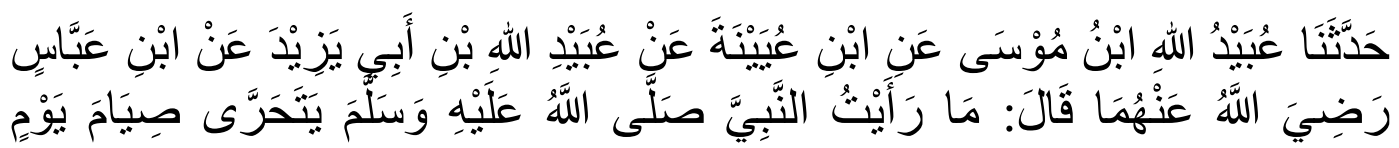

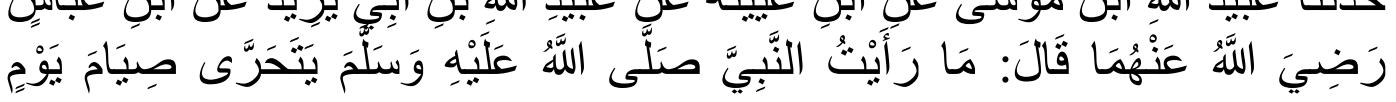

${ }^{13}$ Muhammad bin Ismail al-Bukhari al-Ju'fi Abu Abdillah, Șahị̆h Bukhārī, hadis no 4141, Juz (Bairut, Dar Ibnu Kașir), h. 1634.

${ }^{14}$ Muhammad bin Ismail bin Ibrahim bin al-Mugirah al-Bukhari, Jami' Musnad Sahih alMukhtasar, hadis no. 4142, Juz 6 (Dar Tuk al-Najah), h. 24. 


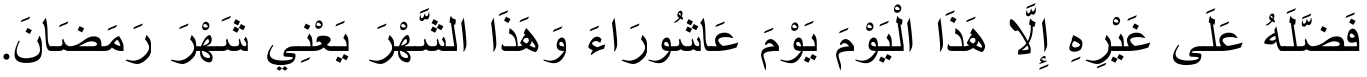

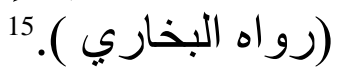

Artinya:

"Telah menceritakan kepada kami 'Ubaidullah bin Musa dari ibn 'Uyaīnah dari 'Ubaīdullah bin Abì Yazìd dari Ibn 'Abbas ra. berkata: "Aku tidak pernah melihat Nabi Muhammad saw. begitu bersemangat puasa pada suatu hari, ia utamakan dari yang lainnya, kecuali hari ini yaitu hari 'āsyürā dan bulan ini, yaitu bulan Ramadhan". (HR Bukhāri)

2. Hadis riwayat Muslim

حدثني قتيبة بن سعيد، حدثنا أبو عو انة عن أبي بشـر، عن حميد بن عبدالرحمن

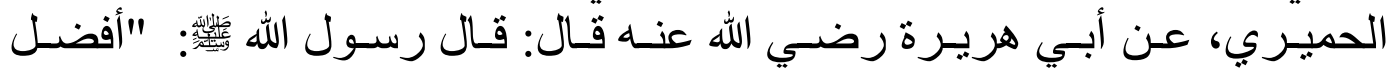

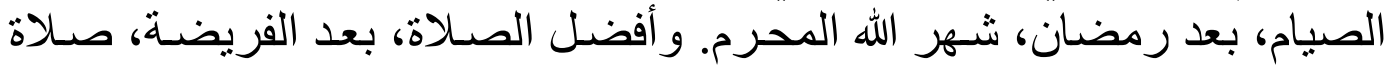
الليل. (رو اه مسلم).

Artinya:

Menceritakan kepadaku Qutaibah bin Sa'id, menceritakan kepada kami Abū Awanah dari Abū Bisyr, dari Humaid bin Abdurrahman al-Humairi, dari Abū Hurairah ra., ia berkata: Rasulullah saw. bersabda: "Sebaik-baiknya puasa setelah Ramadhan adalah puasa pada bulan Muharram. Dan sebaik-baiknya ibadah setelah ibadah wajib adalah shalat malam." (HR Muslim).

وحدثنا الحسن بن علي الحلو اني. حدثنا ابن أبي مريم. حدثنا يحيى بن أيوب.

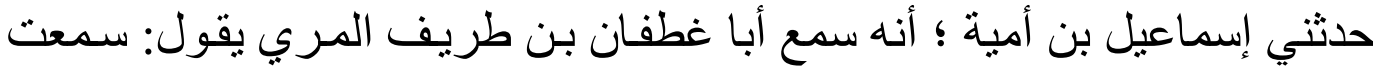

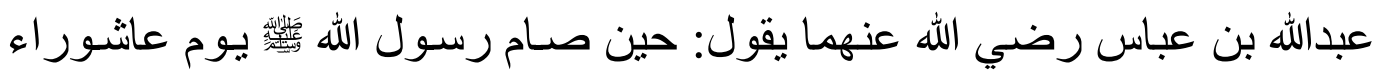

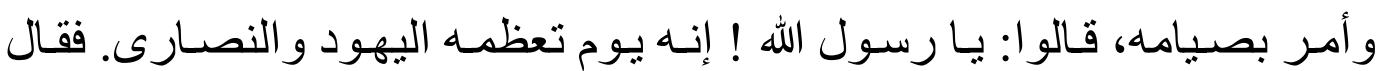

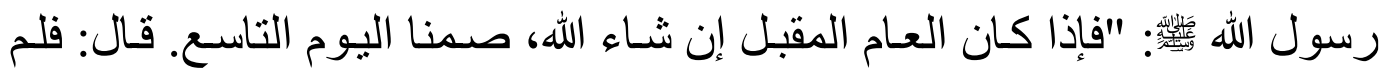

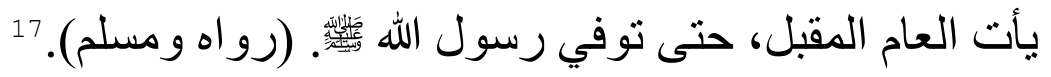

Artinya:

Menceritakan kepada kami al-Hasan bin Ali al-Halwani, menceritakan kepada kami Ibn Abi Maryam, menceritakan kepada kami Yahya bin

${ }^{15} \mathrm{Abu}$ Abdillah Muhammad bin Ismail bin Ibrahim bin al-Mughirah bin Bardizbah alJa'fi al-Bukhari, Sahịị Bukhärī, h. 251.

${ }^{16}$ Muslim bin al-Hajjāj Al-Naisapuri, Șaḥ̄ Mus Muim (Maktabah Syāmilah), hadis no. 1163.

${ }^{17}$ Sahịh Muslim, hadis no. 1134 
Ayyub, menceritakan kepada kami Isma'il bin Umayyah, bahwa Isma'il mendengar Abū Ghathafan bin Tharif al-Murriy berkata: Saya mendengar Abdullah bin Abbas berkata: "Ketika Rasulullah saw. berpuasa 'āsyūrā dan memerintahkan umatnya untuk berpuasa, maka para sahabat bertanya: "Ya Rasulullah, bukankan hari 'āsyürāadalah yang dimuliakan oleh kaum Yahudi dan Nasrani". Maka beliau bersabda: Jika datang tahun depan insya Allah kita akan berpuasa pada hari kesembilan Muharram". Namun Rasulullah saw. wafat dan tidak mendapati tahun depan". (HR Muslim).

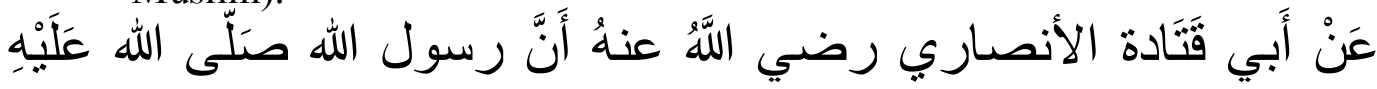

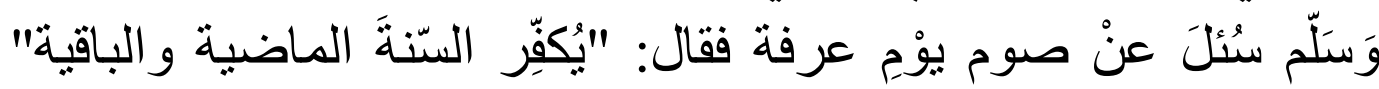

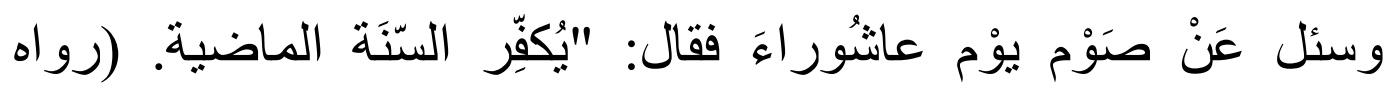
مسلم) مسلمع

Artinya:

Dari Abu Qatadah al-Anshari ra., bahwa Rasulullah saw. ditanya tentang puasa hari "Arafah, beliau bersabda: "Puasa 'Arafah menghapuskan dosadosa satu tahun yang telah lewat dan akan datang. Dan Rasulullah saw. ditanya tentang puasa 'ásyūra, beliau bersabda: "Puasa 'āsyūra dapat menghapuskan dosa-dosa satu tahun yang telah lewat. (HR Muslim).

3. Hadis riwayat al-Nasāi

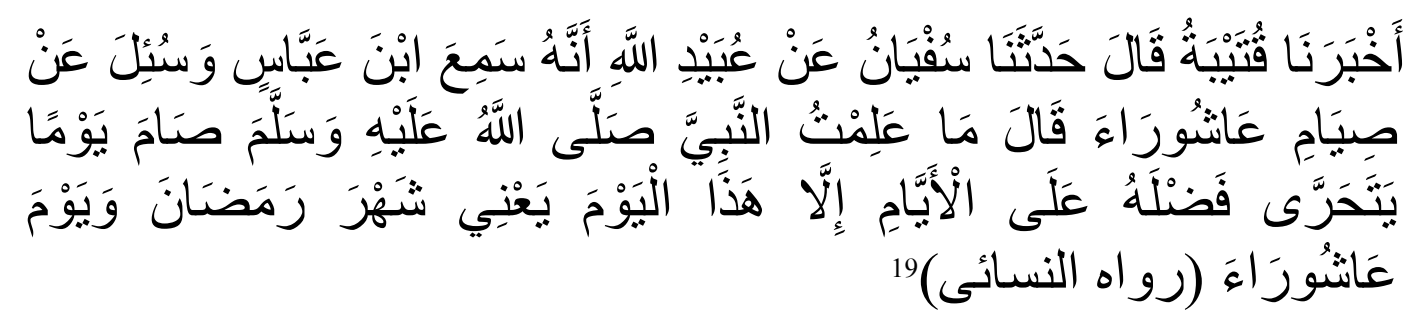

Artinya:

Telah mengabarkan kepada kami Qutaibah dia berkata; telah menceritakan kepada kami Sufyān dari 'Ubaidullah bahwasanya ia mendengar Ibn 'Abbas, dan ditanya tentang puasa 'àsyürá?, ia berkata; "Aku tidak pernah mengetahui Nabi saw. berpuasa di hari yang beliau pilih keutamaannya dibanding hari-hari lain, kecuali hari ini yaitu: bulan Ramadlan dan hari 'ásyürá. (HR Nasai).

\section{Bentuk-bentuk tradisi di Kecamatan Bola Kabupaten Wajo}

\footnotetext{
${ }^{18}$ Muslim bin al-Hajjāj Al-Naisaburi, Șaḥị Muslim (Maktabah Syāmilah), hadis no. 1166.

${ }^{19}$ Ahmad Bin Syuaib Abu Abdirrahman al-Nasai, Sunan al-Nasāi, hadis no 2330, Juz 4 (Hulb, Maktabah al-Matbuah al-Islami), h. 204.
} 
Sebelum membahas lebih lanjut tentang bentuk-bentuk tradisi di Kecamatan Bola Kabupaten Wajo, maka perlu diketahui defenisi tradisi dari berbagai sumber, sebagai berikut:

1. Menurut Kamus Besar Bahasa Indonesia, tradisi adalah adat kebiasaan turuntemurun yang masih dijalankan dimasyarakat dengan anggapan tersebut bahwa cara-cara yang ada merupakan yang paling baik dan benar. ${ }^{20}$

2. Tradisi dalam kamus antropologi sama dengan ada istiadat yang bersifat magis religious dari suatu kehidupan penduduk asli yang meliputi nilai-nilai budaya, norma-norma, hukum dan aturan-aturan yang saling berkaitan. Kemudian menjadi suatu sistem atau peraturan yang sudah menyatu dengan konsep sistem budaya dari suatu kebudayaan untuk mengatur tindakan atau perbuatan manusia dalam kehidupan sosial. ${ }^{21}$

3. Dalam kamus sosiologi, tradisi adalah kepercayaan turun-temurun yang dapat dipelihara. $^{22}$

Dari beberapa defenisi diatas dapat disimpulkan bahwa tradisi adalah memiliki makna yang sama dengan adat istiadat yaitu merupakan suatu adat kebiasaan yang turun temurun dari nenek moyang yang masih dilakukan oleh masyarakat.

Mengenai asal mula adanya tradisi 'āsyürā di Kecamatan Bola Kabupaten Wajo, sampai saat ini belum ada data yang menjelaskan secara pasti tentang asal mula masuknya tradisi 'āsyürā di Kecamatan Bola Kabupaten Wajo. Menurut informan bapak H. Arasy bahwa:

"Tradisi yang biasa dilaksanakan oleh masyarakat Kecamatan Bola Kabupaten Wajo merupakan tradisi nenek moyang yang turun temurun dilaksanakan oleh para orang tua. ${ }^{23}$ bahwa:

Sementara pendapat dari informan lain yaitu bapak Ramli mengatakan

"Tradisi yang dilakukan masyarakat Kecamatan Bola Kabupaten Wajo hanya sekedar melakukan seperti yang pernah dilakukan oleh orang-orang dahulu".

Sedangkan menurut ibu Ruwayah bahwa:

"Tradisi yang dilaksanakan oleh masyarakat Kecamatan Bola Kabupaten Wajo berupa kebiasan-kebiasaan yang dilakukan oleh nenek moyang terdahulu dan masih dilakukan hingga saat ini". ${ }^{25}$

Dari pendapat tersebut dapat disimpulkan bahwa asal mula dari pelaksanaan tradisi di Kecamatan Bola Kabupaten Wajo adalah merupakan

${ }^{20}$ Kamus Besar Bahasa Indonesia (Jakarta: Balai Pustaka, 2007), h. 1208.

${ }^{21}$ Ariyono dan Aminuddin Siregar, Kamus Antropologi (Jakarta: Akademika Presindo, 1998), h. 4.

${ }^{22}$ Soekanto, Kamus Sosiologi (Jakarta: PT Raja Grapindo Persada, 1993), h. 459.

${ }^{23}$ H. Muh. Arasy (68 tahun), Imam Desa, Wawancara, Sanreseng Ade Kecamatan Bola Kabupaten Wajo, 7 Februari 2018.

${ }^{24}$ Ramli (55 tahun), Tokoh Masyarakat, Wawancara, Sanreseng Ade Kecamatan Bola Kabupaten Wajo, 1 Februari 2018.

${ }^{25}$ Ruwayah (40 tahun), Unsur Pendidik, Wawancara, Sanreseng Ade Kecamatan Bola Kabupaten Wajo, 10 Februari 2018. 
kebiasaan-kebiasan turun temurun yang dilakukan oleh nenek moyang sampai sekarang.

Adapun tradisi yang dilakukan oleh masyarakat Kecamatan Bola Kabupaten Wajo pada hari 'àsyüra adalah membuat bubur tujuh macam dan berbelanja perabot rumah tangga.

1. Membuat bubur tujuh rupa

Bubur tujuh macam tersebut terbuat dari tujuh macam bahan makanan, adapun yang biasa dibuat oleh masyarakat Kecamatan Bola Kabupaten Wajo adalah beras ketan, kacang ijo, labu, kacang tanah, pisang, nangka dan ubi jalar. Bubur tujuh rupa tersebut dimaksudkan agar segala sesuatu yang kita lakukan selalu mattuju-tujung yang berarti perbuatan tersebut berjalan lancar sesuai yang diharapkan.

Berdasarkan hasil wawancara dengan bapak H. Syamsuddin menuturkan bahwa:

"Awal dari berlakunya tradisi bubur tujuh macam itu berawal dari peristiwa yang terjadi pada tanggal sepuluh Muharram (hari 'āsyürä). Seperti kisah Nabi Nuh as. beserta para pengikutnya yang terselamatkan dari bencana banjir yang memusnahkan seluruh makhluknya, kecuali yang ada dalam kapal tersebut. Pada saat itu Nabi Nuh as. beserta para pengikutnya merasa sangat kelaparan setelah turun dari kapal, lalu Nabi Nuh as. memerintahkan mereka untuk mengambil bekal yang masih tersisa hingga mencapai tujuh macam biji-bijian. Kemudian mencampurkannya lalu makan bersama-sama dan merasa kenyang. ${ }^{27}$

Pendapat lain diungkapkan oleh ibu Hj. Bungatang mengatakan:

"Tujuan pembuatan bubur tujuh macam ialah untuk disajikan sebagai hidangan pada saat berbuka puasa, selain itu ada juga yang hanya sekadar membuat untuk dimakan bersama. ${ }^{28}$

Hal senada juga diungkapkan oleh ibu Hj. Darnawati menyatakan:

"Pembuatan bubur tujuh macam karena sudah menjadi kebiasan di kampung kami pada bulan Muharram tepatnya pada tanggal sepuluh Muharram merupakan tradisi yang turun temurun dilaksanakan oleh para orang tua. ${ }^{29}$

${ }^{26}$ A. Herman (57 tahun), Kepala Kelurahan, Wawancara, Solo Kecamatan Bola Kabupaten Wajo.

${ }^{27}$ H. Syamsuddin (45 tahun), Imam Desa, Wawancara, Lattimu Kecamatan Bola Kabupaten Wajo, 12 Februari 2018.

${ }^{28} \mathrm{Hj}$. Bungatang (65 tahun) Tokoh Masyarakat, Wawancara, Sanreseng Ade Kecamatan Bola Kabupaten Wajo, 12 Februari 2018.

${ }^{29}$ Hj. Darnawati (42 tahun), Tokoh Masyarakat, Wawancara, Lattimu Kecamatan Bola Kabupaten Wajo, 29 Februari 2018. 
Namun, suatu keterangan yang sedikit berbeda dari para informan yang lain adalah apa yang diungkapkan oleh ibu Ruwayah saat ditanya tentang pembuatan bubur tujuh macam menyatakan bahwa:

"Kami biasanya membuat bubur tujuh macam untuk dibagi-bagikan (bersedekah) kepada tetangga dekat dan untuk mempererat tali silaturahim terhadap sesama".

Dari beberapa keterangan yang berbeda-beda di atas dapat disimpulkan bahwa pembuatan bubur tujuh macam bertujuan untuk dimakan saat berbuka puasa yang merupakan tradisi masyarakat pada tanggal sepuluh Muharram. Selain itu, bubur tujuh rupa juga dibuat untuk dibagi-bagikan kepada keluarga dan termasuk bagian dari sedekah serta untuk mempererat tali silaturahim antar sesama.

2. Berbelanja perabot rumah tangga

Tradisi berbelanja perabot rumah tangga di Kecamata Bola Kabupaten Wajo tidak ada yang tahu sejak kapan tradisi tersebut dimulai. Berbelanja perabot rumah tangga biasanya masyarakat Kecamatan Bola Kabupaten Wajo membeli barang tersebut yang diawali dengan huruf " $p$ " (dalam bahasa bugis) seperti: pesro (passero), pet (panteng), pmutu (pamuttu), ptpi (pattapi), psEri (passering) ${ }^{31}$ dan lain-lainnya. Namun ada juga barang yang dibeli bukan dari awalan " $p$ ". Tetapi kebanyakan yang sering dibeli oleh masyarakat adalah ptpi (pattapi) pesro (passero), dan psEri (passering). ${ }^{32}$ bahwa:

Sementara hasil dari wawancara dengan bapak H. Nasruddin menuturkan

"Apabila memasuki bulan muharram tepatnya pada hari 'āsyūrā (hari kesepuluh Muharram) maka masyarakat di Kecamatan Bola Kabupaten Wajo sangat antusias melaksanakan beberapa tradisi yang sudah menjadi kebiasaan bagi mereka. Salah satunya adalah berbelanja perabot rumah tangga sesuai dengan kadar ekonominya, walaupun hanya satu buah barang yang dibeli karena keadaan ekonominya sangat minim karena mereka menganggap bahwa hari tersebut merupakan hari yang sangat istimewa serta merupakan mappassagena balanca (dalam istilah bugis)". 33

Dalam artian, masyarakat Kecamatan Bola Kabupaten Wajo menganggap bahwa hari 'ásyüra mengandung sisi keberkahan khususnya pada pembelian perabot rumah tangga. Pada pembelian perabot rumah tangga tersebut diawali dengan huruf " $p$ " (dalam bahasa bugis).

\footnotetext{
${ }^{30}$ Ruwayah (40 tahun), Unsur Pendidik, Wawancara, Sanreseng Ade Kecamatan Bola Kabupaten Wajo, 10 Februari 2018.

31 pesro dalam bahasa Indonesia berarti timba. petdalam bahasa Indonesia berarti ember. pmutu dalam bahasa Indonesia berarti wajan. ptpi dalam bahasa Indonesia berarti tampi. dan psEri dalam bahasa Indonesia berarti sapu.

${ }^{32}$ H. Muh. Arasy (68 tahun), Imam Desa, Wawancara, Sanreseng Ade Kecamatan Bola Kabupaten Wajo, 7 Februari 2018.

${ }^{33}$ H. Nasruddin (49 tahun), Kepala Desa, Wawancara, Sanreseng Ade Kecamatan Bola Kabupaten Wajo, 2 Februari 2018.
} 


\section{Pengamalan Hadis tentang Hari ‘Asyürā di Kecamatan Bola Kabupaten Wajo}

Hadis sebagai sumber hukum Islam yang kedua setelah Alquran, merupakan pedoman dan tuntunan bagi umat Islam dalam melakukan seluruh aktivitasnya, baik masalah ibadah, budi pekerti, sosialisasi dalam kehidupan bermasyrakat, dan lain sebagainya. Hadis yang juga berfungsi sebagai pedoman hidup manusia yang bersumber dari Nabi saw., banyak yang dipraktekkan dalam kehidupan masyarakat, termasuk masyarakat di Kecamatan Bola Kabupaten Wajo.

Sehubungan dengan pengamalan hadis-hadis hari 'āsyūrā di Kecamatan Bola Kabupaten Wajo, pada dasarnya telah diterapkan, namun kebanyakan dari mereka tidak mengenal istilah hari 'āsyürä, mereka hanya mengenal istilah puasa sepuluh Muharram dan yang melaksanakannya bagi masyarakat yang mengetahui tentang disunnahkan berpuasa pada hari kesepuluh bulan Muharram.

Adapun amalam-amalan yang biasa dilakukan masyarakat Kecamatan Bola Kabupaten Wajo adalah, sebagai berikut:

4. Berpuasa

Puasa merupakan perintah Allah swt. yang wajib kita laksanakan sebagai umat Islam, baik laki-laki maupun perempuan. Sebagaimana firman Allah swt. QS al-Baqarah/2: 183

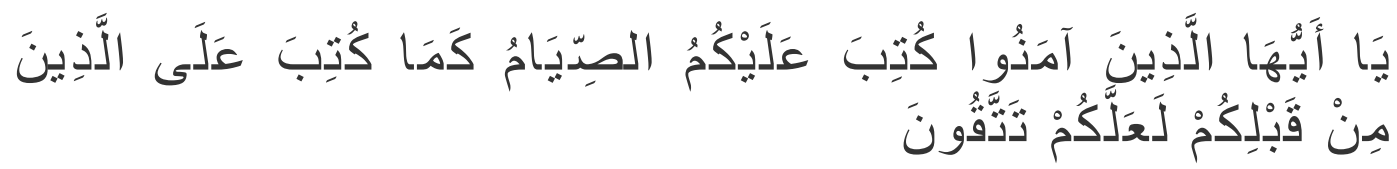

Terjemahnya:

Hai orang-orang yang beriman, diwajibkan atas kamu berpuasa sebagaimana diwajibkan atas orang-orang sebelum kamu agar kamu bertakwa. $^{34}$

Sedangkan hadis yang menerangkan tentang kewajiban berpuasa adalah sebagaimana riwayat Ibn Umar yang mengatakan:

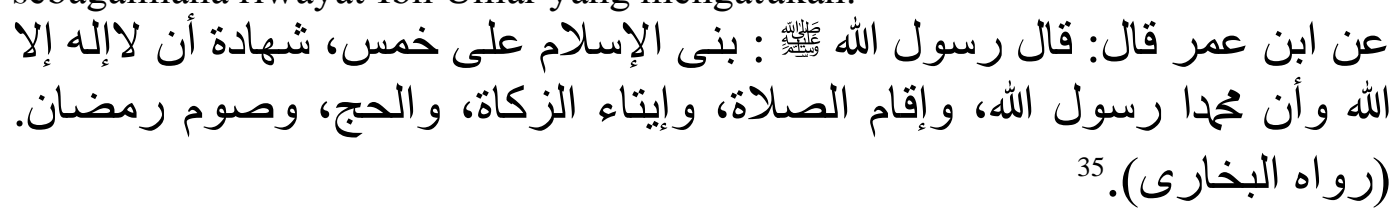

Artinya:

Dari Ibn Umar berkata: Rasulullah saw. bersabda: Islam dibangun atas

lima dasar; persaksian tidak ada Tuhan Selain Allah swt. dan sesungguhnya Muhammad adalah utusan Allah, mendirikan șalat, mengeluarkan zakat, naik haji dan berpuasa pada bulan ramadhan. (HR Bukhari).

Akan tetapi puasa yang dimaksud disini adalah puasa sunnah yaitu apabila kita mengerjakan mendapatkan pahala bilamana kita meninggalkan tidak berdosa. Salah satu puasa yang disunnahkan oleh Allah swt. adalah puasa hari 'àsyürá yang merupakan puasa sunnah yang dilakukan sekali setahun (puasa

\footnotetext{
${ }^{34}$ Kementerian Agama RI, Alquran dan Terjemahnya (Cet. I; Bandung: PT Cordoba Internasional Indonesia, 2012), h.

${ }^{35}$ Ibn Hajr Al-Asqalān, Fath al-Bāri Syarah Șahīh al-Bukhari, Juz I (Beirut: Dār al-katab al-Ilmiyah, 2003), h. 68.
} 
tahunan). Waktu pelaksanaan puasa 'āsyürā yang biasa dilakukan oleh warga masyarakat Kecamatan Bola Kabupaten Wajo adalah pada hari kesepuluh bulan Muharram (hari 'àsyürāa).

Menurut ibu Andi Sariwana:

"Masyarakat yang ada di Kecamatan Bola Kabupaten Wajo, umumnya orang awam sehingga pengetahuan mereka sangat kurang terkhusus mengenai hadis hari "asyüra (sepuluh Muharram)".

Namun, suatu keterangan dari para informan yang lain adalah apa yang diungkapkan oleh bapak H. Syamsuddin, saat ditanya tentang pengamalan hadis hari 'àsyüra dia berkata:

"Masyarakat yang ada di sekitar kampung kami kurang sekali mengetahui hadis tentang hari 'assyūra, disebabkan kurangnya pendidikan mereka terhadap ilmu pengetahuan agama. Sehingga pengamalan hadis tentang hari 'àsyüra masih sebahagian kecil yang melaksanakannya".

Begitu pula, suatu keterangan yang senada dengan yang diungkapkan oleh bapak Sulhan, mengatakan bahwa:

"Mengenai pengamalan hadis tentang hari 'āsyūrā di Kecamatan Bola Kabupaten Wajo sangat sedikit masyarakat yang menarapkannya, kecuali bagi masyarakat yang paham tentang hadis tersebut, serta mengetahui keutamaan puasa sunnah pada hari itu.

Dengan berlandaskan kepada hadis berikut:

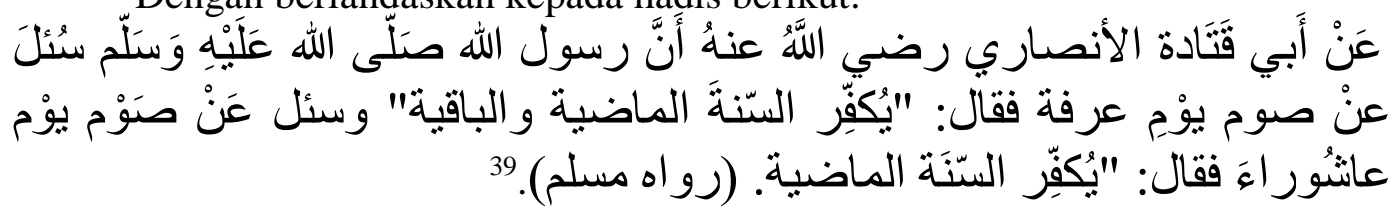

Artinya:

Dari Abu Qatadah al-Anshari ra, bahwa Rasulullah saw. ditanya tentang puasa hari "Arafah, beliau bersabda: "Puasa 'Arafah menghapuskan dosadosa satu tahun yang telah lewat dan akan datang. Dan Rasulullah swt. ditanya tentang puasa 'àsyūrá, beliau bersabda: "Puasa 'àsyūrá dapat menghapuskan dosa-dosa satu tahun yang telah lewat. (HR Muslim).

Dari pendapat tersebut dapat disimpulkan bahwa masyarakat di Kecamatan Bola Kabupaten Wajo, hanya sebahagian kecil yang mengaplikasikan

\footnotetext{
${ }^{36}$ Andi Sariwana (53 tahun), Camat Bola, Wawancara, Solo Kecamatan Bola Kabupaten Wajo, 26 Januari 2018.

${ }^{37}$ H. Syamsuddin (45 tahun), Imam Desa, Wawancara, Lattimu Kecamatan Bola Kabupaten Wajo, 12 Februari 2018.

${ }^{38}$ Sulhan (45 tahun), Imam Kelurahan Solo (usia tahun), Wawancara, Solo Kecamatan Bola Kabupaten Wajo, 1 Februari 2018.

1166.

${ }^{39}$ Muslim bin al-Hajjāj Al-Naisapuri, Șaḥ̄ Ṃ Muslim (Maktabah Syāmilah), hadis no:
} 
hadis tentang disunnahkannya berpuasa pada hari kesepuluh bulan Muharram (hari âsyürä), disebabkan karena belum paham dan mengerti tentang hadis hari 'àsyūrā serta keutamaannya.

5. Berzikir, dan mengaji

Masyarakat Kecamatan Bola Kabupaten Wajo, biasanya melakukan zikir dan mengaji pada bulan muharram tepatnya tanggal sepuluh Muharram. Menurut bapak H. Syamsuddin bahwa:

"Biasanya kami mengisi hari 'āsyūrā dengan memperbanyak melakukan zikir serta mengaji di mesjid, walaupun hanya bersifat individu. ${ }^{40}$

Sementara bapak Sulhan mengatakan bahwa:

"Berzikir dan mengaji pada bulan muharram dengan tujuan untuk mengawali kehidupan di dunia ini dengan membuka lembaran-lembaran yang baru serta melakukan perbuatan yang baik dan meninggalkan perbuatan yang buruk karena bulan tersebut merupakan awal dari tahun baru Hijriah, dan pada hari kesepuluh merupakan hari yang sangat istimewa pada umat Islam".

6. Bersedekah

Dari hasil wawancara oleh ibu Ruwayah bahwa:

"Kebiasaan berbagi bubur tujuh macam kepada tetangga dekat merupakan sedekah dan dapat mempererat tali silaturrahim". bahwa:

Sedangkan pendapat lain yang dikemukaknan oleh ibu Kati Mappiasse

"Biasanya bukan hanya bubur tujuh macam yang dibagi-bagikan kepada tetangga dekat tetapi berupa perabot rumah tangga, seperti tempattempat makan (mangkuk dan timba). ${ }^{43}$

Namun, suatu keterangan yang lain dari para informan adalah apa yang diungkapkan oleh bapak H. Arasy bahwa:

"Kegiatan yang dilakukan masyarakat Kecamatan Bola Kabupaten Wajo pada tanggal sepuluh Muharram sebagai tanda rasa syukur kepada Allah swt. dan juga merupakan hari yang disunnahkan untuk memperbanyak ibadah. Karena hari ini sebagai salah satu hari istimewa bagi umat Islam dimana hari tersebut juga merupakan hari yang bersejarah. Seperti kisah

${ }^{40}$ H. Syamsuddin (45 tahun), Imam Desa, Wawancara, Lattimu Kecamatan Bola Kabupaten Wajo, 12 Februari 2018.

${ }^{41}$ Sulhan (45 tahun), Imam Kelurahan Solo, Wawancara, Solo Kecamatan Bola Kabupaten Wajo, 1 Februari 2018.

${ }^{42}$ Ruwayah (40 tahun), Unsur Pendidik, Wawancara, Sanreseng Ade Kecamatan Bola Kabupaten Wajo, 10 Februari 2018.

${ }^{43}$ Kati Mappiasse (57 tahun), Tokoh Agama, Wawancara, Kecamatan Bola Kabupaten Wajo, 10 Februari 2018. 


\section{HADIS-HADIS TENTANG PUASA'ATSYURA \\ (Suatu Kajian Living Sunnah di Kecamatan Bola Kabupaten Wajo)}

Nabi Musa a.s. terselamatkan dari kejaran Fir'aun, Nabi Nuh a.s. beserta kaumnya terselamatkan dari bencana banjir. yaitu:

Pernyataan di atas senada dengan yang diungkapkan oleh bapak Sulhan

"Dimana hari kesepuluh bulan Muharram atau hari 'assyüra kita dianjurkan untuk nmemperbanyak perbuatan-perbuatan yang baik dimana hari tersebut merupakan hari yang bersejarah, yang penuh dengan kenangan dan pelajaran yang berharga dari peristiwa-peristiwa penting yang pernah terjadi.

Dari beberapa pendapat tersebut dapat disimpulkan bahwa pada hari àsyüra, masyarakat Kecamatan Bola Kabupaten Wajo tidak hanya melaksanakan ibadah sunnah puasa serta zikir dan mengaji, tetapi juga mengeluarkan sebahagian rezeki yang mereka miliki.

\section{PENUTUP}

Berdasarkan penjelasan dan uraian yang telah dikemukakan sebelumnya, maka dapat dirumuskan beberapa poin kesimpulan sebagai jawaban atas tiga permasalahan pokok yang diangkat dalam tulisan ini, yaitu:

1. Ada beberapa hadis yang menggambarkan tentang disunnahkannya berpuasa pada hari 'ásyūra. Salah satunya adalah hadis yang menjelaskan bahwa Nabi Muhammad saw. telah melaksanakan puasa pada hari 'äsyūrā sebelum hijrah ke Madinah. Kemudian saat Nabi Muhammad saw. berada di Madinah, beliau melihat kaum Yahudi dan Nsrani berpuasa pada hari itu, maka Nabi Muhammad saw. juga melaksanakn puasa pada hari itu dan memerintahkan pula kepada kaumnya untuk berpuasa pada hari itu.

2. Bentuk-bentuk tradisi 'āsyürā di Kecamatan Bola Kabupaten Wajo

Tradisi adalah suatu adat istiadat yang turun temurun dari nenek moyang yang masih dilakukan sampai sekarang.

Adapun bentuk-bentuk tradisi 'āsyūrā di Kecamatan Bola Kabupaten Wajo yaitu, sebagai berikut:

a. Membuat bubur tujuh macam

Dalam pembuatan bubur tujuh macam tersebut terbuat dari tujuh macam bahan makanan, yaitu beras ketan, kacang ijo, labu, kacang tanah, pisang, nangka dan ubi jalar. Semua bahan-bahan tersebut akan dicampurkan dengan santan dan gula merah. Bubur tujuh rupa tersebut bertujuan untuk dimakan saat berbuka puasa yang merupakan tradisi masyarakat pada tanggal sepuluh Muharram. Selain itu, bubur tujuh macam juga dibuat untuk dibagi-bagikan kepada keluarga atau tetangga dekat untuk mempererat tali silaturahim antar sesama.

b. Berbelanja perabot rumah tangga

\footnotetext{
${ }^{44}$ H. Muh. Arasy (68 tahun), Imam Desa, Wawancara, Sanreseng Ade Kecamatan Bola Kabupaten Wajo, 7 Februari 2018.

${ }^{45}$ Sulhan (45 tahun), Imam Kelurahan Solo (usia tahun), Wawancara, Solo Kecamatan Bola Kabupaten Wajo, 1 Februari 2018.
} 
Pada biasanya masyarakat Kecamatan Bola Kabupaten Wajo saat berbelanja perabot rumah tangga pada hari 'äsyürā mereka membeli barang tersebut yang diawali dengan huruf " $p$ " (dalam bahasa bugis), yang termasyhur adalah ptpi (pattapi) pesro (passero), dan psEri (passering).

3. Pengamalan hadis 'àsyürà di Kecamatan Bola Kabupaten Wajo

Masyarakat Kecamatan Bola Kabupaten Wajo ketika mengaplikasikan hadis 'assyüra, mereka mengamalkan melalui berbagai macam cara, yaitu: Berpuasa, zikir dan mengaji, serta bersedekah. Namun, kenyataannya masyarakat Kecamatan Bola Kabupaten Wajo masih sangat minim yang merealisasikan khususnya pada hari 'àsyüra.

Inti dari kesimpulan diatas bahwa dalam pengaplikasian sepuluh Muharram (hari āsyüra) masyarakat Kecamatan Bola Kabupaten Wajo sangat antusias melestarikannya dengan berbagai tradisi, seperti tradisi berbelanja perabot rumah tangga dan pembuatan bubur tujuh rupa. Dalam tradisi bubur tujuh macam dan berbelanja alat rumah tangga hendaknya tidak menggeser tuntunan Rasulullah saw. untuk melaksanakan puasa sunnah di hari tersebut. Hal yang sangat disayangkan apabila masyarakat Kecamatan Bola Kabupaten Wajo yang sangat antusias melestarikan tradisi tersebut justru meninggalkan sunnah junjungan kita Rasulullah saw.

\section{DAFTAR PUSTAKA}

\section{Alquran al-Karim}

Arikunto, Suharsimi. Prosedur Penelitian: Suatu Pendekatan Praktek. Cet. XIII; Jakarta: Rineka Cipta, 2006.

Al-Asqalān, Ibn Hajr. Fath al-Bāri Syarah Ṣahīh al-Bukhari. Juz IBeirut: Dār alkatab al-Ilmiyah, 2003.

Al-Asqalāni, Ibnu Hajr Buh̄̄g al-Marām. Semarang: Toha Putra,t.t.

Anas, Imam Mālik bin. al- Muwatța’. Bairut: Dār al-Fikr, 1989.

Ahmad, Muhammad dan Muzakir, M. Ulumul Hadis. Cet. III; Bandung: Pustaka Setia, 2004. 
Arikunto, Suharsimi. Manajemen Penelitian. Cet. IX; Jakarta: Rineka Cipta, 2007.

Ali, Muhammad. Penelitian Kependidikan Prosedur dan Strategi. Cet. III; Bandung: Angkasa, 1985.

Ariyono dan Siregar, Aminuddin. Kamus Antropologi. Jakarta: Akademika Presindo, 1998.

A. Partanto, Pius. Kamus Ilmiah Populer. Cet. I; Surabaya: Arkola, 2001.

Al-Bukhārì, Abū 'Abdullah Muhammad Ibn Ismā'il. Matan al-Bukhāri, Jilid II. Surabaya: Nurul Huda.

- Muhammad bin Ismail bin Ibrahim bin al-Mughirah. Sahih alBukhäri, J Jilid II. Istanbul: Dar Sahnun, 1413 H/1992.

. Șahịh al-Bukhārī, Maktabah Syamilah, Juz. III.

Bahruddin. "Hadis-hadis hari Āsyūrāa dan Implikasi Hukumnya "dalam Masyarakat Sulawesi-Selatan (Suatu Kajian Kritik Hadis).

Makassar: Fakultas Usuluddin UIN Alauddin, 2000.

Al-Barry, M. Dahlan Y. dan L. Sofyan Yacob. Kamus Induk Ilmiah Seri Intelektual. Cet. I; Surabaya: Target Press, 2003.

Bungin, Burhan. Penelitaian Kualitatif: Komunikasi, Ekonomi, Kebijakan Publik, dan Ilmu Sosial Lainnya. Cet. III; Jakarta: Kencana Prenada Media Group, 2009.

. Metodologi Penelitaian Kualitatif Aktualisai Metodologis Ke Arah Ragam Varian Kontemporer. Cet. I; Jakarta: Rajagrafindo Persada, 2010.

Dāud, Alfāni. Islam dan Masyarakat Banjar; Diskripsi dan Analisis Kebudayaan Banjar. Jakarta: Rajawali Press, 1997.

Al-Damyathi, Al-Bakri. I'anah al-Thalibin, Juz. II. Semarang: Maktabah Thaha Putra.

Faisal, Sanafiah. Format-format Penelitan Sosial. Cet. I; Jakarta: Erlangga, 2001.

Hasan, Mustofa. Ilmu Hadis . Cet. I; Bandung: Pustaka Setia, 2012.

Al-Ḥamīd, Muhammad Muhi al-din 'Abdu. Sunan Abū Dāud, no. 2445, Jilid I. Surabaya: Al-Hidayah.

Hurgronje, Snouck. Mekka in the Latter Part of the 19 th Century: Daily Life, Customs and Learning. Jilid 1; Leiden: Late E. J. Brill Ltd, 1931.

Al- Haḍrami, sayyid Abdurrahman bin Muhammad. Bugyah al-Mustarsyidin. Indonesia: Dar Ihyā al-Kutub al-Arabiyah,t.t. 
Al-Haitami, Ibn Hajar. Tuhfah al-Muḥtāj, Jilid I. Beirut: Dar al-Kutub al'Ilmiyah,t.t.

Kutub al-'Ilmiyah,1997.

http://Van.9f.Com/Asyuro.Htm Asyürā dalam Perspektif Islam, Syi'ah dan Kejawen, diakses tanggal 28 Desember 2017.

http://suryadilaga.wordpress.com/2010/01/26, model-model living hadis, diakses pada tanggal 15 Januari 2018.

http//ilmu hadis.blogspot.com.

http://suryadilaga.wordpress.com/2010/01/26/model-model-living-hadis diakses pada tanggal 15 Januari 2018.

Al-Hasani, Sayyid Muhammad Alawi al-Maliki Mafãhīm yajibu An-Tușạiḥa. Kairo: Dar Jawāmi' al-Kalim ad-Dirāsah, t.t.

Idrus, Muhammad. Metode Penelitian Ilmu Sosial. Edisi Revisi.Yogyakarta: Erlangga, 2009.

Al-Jāwi, Muhammad Nawāwi bin Umar. Nihāyah az-Zain, Jilid I. Maktabah Syāmilah.

Kementerian Agama RI, Alqǖn dan Terjemahnya. Cet. I; Bandung; PT Cordoba Internasional Indonesia, 2012.

Khon, Abdul Majid. Takrij dan Metode Memahami Hadis. Ed. I, Cet. I; Jakarta: Amzah, 2014.

Khairuddin, Ahmad. "Āsyūrā' Antara Doktrin, Historis dan Antropologis Perspektif Dakwah Pencerahan." Jurnal. UIN-Antasari. Ac. Id (09 Oktober 2017).

Kas̀īr , Ibn. Tafsìr alqurān al- 'Azīm, Jilid IV. Maktabah Syāmilah.

Kamus Besar Bahasa Indonesia. Jakarta: Balai Pustaka, 2007.

Mansyur, M, dkk. Metodologi Penelitian Living Qurān dan Hadis. Cet. I; Yogyakarta: TH Press, 2007.

Mardalis. Metode Penelitian: Suatu Pendekatan Proposal. Cet. IX; Jakarta: PT Bumi Aksara, 2007.

Mantra, Ida Bagoes. Filsafat Penelitian dan Metode Penelitian Sosial. Yogyakarta: Pustaka Pelajar, 2004.

Moleong, Lexy J. Metode Penelitian Kualitatif. Cet. XXVI; Bandung: PT Remaja Rosdakarya, 2009.

Miles dan Huberman. Analisis Data Kualitatif tentang Metode-metode Baru, Terj. Tjejep Rohendi Rohidi. Jakarta: UI Press, 1992. 
Al-Maliki, Muhammad Alawi. Ilmu Usul Hadis. Cet. III; Yogyakarta: Puataka Pelajar, 2012.

Muslim. Sahịh Muslim, Juz. II. Maktabah Syamilah.

Nurhayati dan Attamimi, Suraya. Tradisi 'Asyūrā Pada Masyarakat Muslim Kota Palu Dalam Perspektif Syi'ah, vol. 1, no. 1 (Diakses 9 Desember 2017).

Al-Nawāwi. Al-Majmū' Syarh al-Muhażża, Jilid VI. Beirut: Dar Ālim al-Kutub, 2003.

Al-Naisapuri, Muslim bin al-Hajjāj. Șaḥịh Muslim. Maktabah Syāmilah.

Nawawi, Hadari dan Hadari, Martini. Instrumen Penelitian Bidang Sosial. Cet. II; Yogyakarta: Gadjah Mada University Press. 2006.

Al-Qardhawiy, Yusuf. Taysir al-Fiqh li al-Muslim al-Mu'asharah fi Dau alQur'an wa al-Sunah. Terj. Mizrawi, Zuhairi dan Rahman, Imaduddin. Fiqh Taysir: Metode Praktis Mempelajari Fiqhi. Jakarta: Pustaka alKautsar, 2001.

Rahman, Fazlur. Revival and reform in Islam, terj. Aam Fahmia, Gelombang Perubahan dalam Islam: Studi tentang Fundamentalisme Islam. Cet. II; Jakarta: PT Raja Grafindo Persada, 2001.

Suryadi dan Suryadilaga, Muhammad Alfatih. Metodologi Penelitian Hadis. Cet. I; Yogyakarta: TH-Press, 2012.

Sugiyono. Metode Penelitian Pendidikan; Pendekatan Kuantitatif, Kualitatif, dan R\&D. Cet. XII; Bandung: Alfabeta, 2011. . Metode Penelitian Pendidikan . Cet. X; Bandung: Alfabeta, 2010.

. Metode Penelitian Kombinasi: Mixed Methods. Cet. III; Bandung: Alfabeta, 2012.

Salim, Abd. Muin. Metodologi Ilmu Tafsir. Cet. III; Yogyakarta: Teras, 2010.

Subagyo, Joko. Metode Penelitian dalam Teori dan Praktek. Cet. II; Jakarta: Rineka Cipta, 1997.

Surakhmad, Winarno Dasar-dasar dan Tehnik Research. Bandung: Tarsito Karya, 1990.

Suparta, Munzier. Ilmu Hadis. Cet. III; Jakarta: PT. Raja Grafindo Persada, 2002.

Al-San‘āni, Subul al-Salām, jilid II. Mesir: Maktabah Muṣṭafā al-Bābi al-Halabi, 1960.

Soekanto. Kamus Sosiologi. Jakarta: PT Raja Grapindo Persada, 1993.

Sanjaya, Wina. Penelitian Tindakan Kelas. Jakarta: Prenada Media Group, 2009. 
Tim Penyusun Karya Ilmiah UIN Alauddin Makassar, Pedoman Penelitian Karya Tulis Ilmiah: Makalah, Skripsi, Tesis, Disertasi, dan Laporan Penelitian. Cet. II; Makassar: UIN Alauddin Makassar, 2016.

Wehr, Hans. A Dictionary of Modern Written Arabic. Ithaca New York, 1976. 